Review Article

\title{
Collaborative Cloud Manufacturing: Design of Business Model Innovations Enabled by Cyberphysical Systems in Distributed Manufacturing Systems
}

\author{
Erwin Rauch, ${ }^{1}$ Sven Seidenstricker, ${ }^{1}$ Patrick Dallasega, ${ }^{1}$ and Robert Hämmerl ${ }^{2}$ \\ ${ }^{1}$ Faculty of Science and Technology, Free University of Bozen-Bolzano, Universitätsplatz 5, 39100 Bolzano, Italy \\ ${ }^{2}$ Institute of Human Factors and Technology Management, University of Stuttgart, Nobelstraße 12, 70569 Stuttgart, Germany \\ Correspondence should be addressed to Erwin Rauch; erwin.rauch@unibz.it
}

Received 17 June 2016; Revised 14 September 2016; Accepted 27 September 2016

Academic Editor: Ching-Chow Yang

Copyright (C) 2016 Erwin Rauch et al. This is an open access article distributed under the Creative Commons Attribution License, which permits unrestricted use, distribution, and reproduction in any medium, provided the original work is properly cited.

Collaborative cloud manufacturing, as a concept of distributed manufacturing, allows different opportunities for changing the logic of generating and capturing value. Cyberphysical systems and the technologies behind them are the enablers for new business models which have the potential to be disruptive. This paper introduces the topics of distributed manufacturing as well as cyberphysical systems. Furthermore, the main business model clusters of distributed manufacturing systems are described, including collaborative cloud manufacturing. The paper aims to provide support for developing business model innovations based on collaborative cloud manufacturing. Therefore, three business model architecture types of a differentiated business logic are discussed, taking into consideration the parameters which have an influence and the design of the business model and its architecture. As a result, new business models can be developed systematically and new ideas can be generated to boost the concept of collaborative cloud manufacturing within all sustainable business models.

\section{Introduction}

Due to increasing international competition companies must work continuously to increase their productivity. However, the market demand for ever higher product individuality brings most enterprises into the dilemma of being able to produce small lot sizes economically. The term "Industry 4.0 " is actually highly discussed as a vision in research and industry to revolutionize production management and the factory of the future. After mechanization, electrification, and computerization of industrial production we are now at the beginning of a new epoch in production, where web technology and intelligent automation as well as digitalization support the development of so-called cyberphysical systems (CPS) [1].

So-called distributed manufacturing systems (DMS) represent an ideal approach to meet actual challenges regarding individualization of products, customer proximity, or a more sustainable production. Distributed manufacturing has been identified as one of the main drivers for the design of the "factory of the future" and was highlighted by the United Nations Industrial Development Organization as one of the leading emerging technologies for the future [2]. The evolution of manufacturing cooperation between different enterprises leads to an extension of DMS characteristics. The collaborating companies build up production networks. Such collaborative networks can be organized in the factory of the future through collaborative cloud manufacturing using the emerging cloud computing technology as a digital platform for data exchange and collaboration between customer and companies and between companies themselves in a network of small DMS-production units. Distributed systems have incorporated many systems and new technologies that are compatible with collaboration tools for optimizing processes. More and more companies are opting for an on-demand service model based on the cloud computing paradigm to transform their costs of infrastructure investment into variable costs. This change in the economic model is having an important impact on the companies' cost of accessing technology [3]. Under this aspect it is important to develop 
future frameworks and models for cyberphysical systems to enable a cloud-based production on demand of manufacturing networks for flexible, adaptable, and geographically distributed production units.

Cyberphysical systems are enablers for changing business logic and value chains, with the conjunction of cyberphysical systems and the development of new business models facilitating the creation of disruptive innovations. Research into business model innovations has increased enormously in recent years. The sophisticated combination of changed value generation, changed value capture, and the sharing of added value are the leverage for disruptive innovations. There is, as yet, no definitive definition of the term "business model"; however, in the main, researchers assume that business model describes the logic of doing business by asking the following questions: What is the value proposition for customers? How can revenue be achieved? Which technologies and manufacturing units are used and which partners and networks should be included?

The systematic development process and answering these questions are the task of business model innovation, which can be described as a "search of new logics ... and new ways to create and capture value" [4]. To reduce complexity and give a better understanding of the mechanism of business logic, a business model consists of different business model elements. Just as there are many different definitions of the term "business model," different understandings exist regarding which business model elements describe a business model [5]. The majority of approaches use between three and nine business model elements in their frameworks. This paper uses an approach based on four elements which are particularly suitable within distributed manufacturing systems and distinguishes "value proposition" and "revenues" and "value chain and processes" as well as "technologies, competencies, and key resources."

The technical possibilities enabled by cyberphysical systems require new business logic and, in particular, the need to define other architectures in value generating and capturing [6]. Therefore, the focus of this paper is specifically the business model elements "value proposition" and "revenues," which are applied and discussed for collaborative manufacturing as a concept of distributed manufacturing systems enabled by cyberphysical systems.

\section{State of the Art and Research}

In Section 2.1, the concept of distributed manufacturing (DM) and distributed manufacturing systems (DMS) is explained from a theoretical point of view based on a literature research. In addition, Section 2.2 reviews the actual research activities around the emerging topic of Industry 4.0 and cyberphysical systems (CPS).

\subsection{Theoretical Background of Distributed Manufacturing} Systems. Distributed manufacturing is a scheme gaining increasing popularity in the field of production science. Actually, "distributed manufacturing" is a highly discussed topic in research and practice. Manufacturing is no longer organized in traditional structures of globalized mass production in centralized production facilities. Due to long delivery times and supply chains, the rise in logistics cost and $\mathrm{CO}_{2}$ emissions, a shift from standardized products towards individual or mass-customized goods, and finally the actual trend of cloud-based manufacturing, the concept of distributed manufacturing seems to be a promising topic. Through future decentralized "glocal" production in distributed microproduction facilities, connected with each other, goods will be able to meet local needs and to be delivered quickly and in a more sustainable way [7]. So-called "glocal" production combines the goals of global market development and the fulfilment of local customer requirements [8]. The change from centralized manufacturing units towards decentralized and geographically dispersed production units in virtual production networks shows a highly promising strategy in production science. The following six trends were identified by the authors as some of the most important reasons for an increasing interest in distributed manufacturing systems [7]:

(i) Megatrend Sustainability. Manufacturing systems are to be designed in a way that products can be produced economically and at the same time environmental burdens caused by long transport distances could be minimized.

(ii) Rising Logistics Costs. Production systems with geographically dispersed production facilities will be able to overcome this challenge, reducing the distance between manufacturing location and customer.

(iii) Mass Customization. Mass customization is the answer to an increasing individualization of customer request in combination with the restriction that prices have to be nearly the same as those of standard products.

(iv) Democratization of Design. Centralized manufacturing locations will be substituted by decentralized manufacturing systems and networks, where only data will be transported over long distances, while the locally produced product needs only logistics structure for last-mile transport.

(v) Market and Customer Proximity. Responding to local and individual needs of customers manufacturers will be able to reach new markets through small and flexible manufacturing structures in the vicinity of the consumer.

(vi) Regionalism and Authenticity. Dynamics in regional economic cycles are becoming stronger. For this reason, in sensible niche markets, decentralized production structures will play an important role in the future.

Developing product variants with respect to satisfying diverse customer needs with reasonable costs in terms of mass customization has been recognized as a new paradigm for today's manufacturing $[9,10]$. The concept of decentralized minifactories has specially been developed to support mass customization [11]. Innovative production concepts and emerging digital technologies replace traditional network structures. For this purpose, it is necessary in the future to 
develop modern concepts and models for virtually connected production networks with distributed production units offering personalized products to local customers considering the aspects of cost, time, $\mathrm{CO}_{2}$ emissions, energy consumption, and quality [11]. Manufacturing system based on a minifactory approach is one of the modern pervasive production models providing tailored products with low cost and short delivery time [12]. In this context, only how to design and how to plan decentralized production networks for masscustomized products generally, as discussed in $[13,14]$, in a scalable and modular way [15] were examined. Seregni et al. [16] and Zanetti et al. [12] address the concept of minifactories and describe a "distributed minifactories network" in the Italian furniture industry of SMEs. Such manufacturing systems are a response to demand for customized products with low cost and fast delivery time. Rauch et al. [17] develop the idea of minifactory networks, introducing the concept of Mobile Factory Networks (MFN), in which mobile and agile minifactories can be moved to the place of consumption or resource location.

A new form of distributed manufacturing system is born through the recent progress in additive manufacturing (3Dprinting-technology). So-called desktop factories are playing increasingly significant roles in supporting on-demand manufacturing of customized products. Cloud manufacturing $(\mathrm{CM})$ has been recognized as a promising paradigm for the next generation of manufacturing systems. Due to the novel technical possibilities in additive manufacturing, the topic of cloud manufacturing recently arose in combination with distributed manufacturing [18, 19]. Yao et al. [20] present a conceptual model of cloud-based desktop factories that provides a promising approach to aggregating microfactories into a cyberphysical virtual manufacturing society in the future. Such small scale production systems show an ideal approach for DIY (Do-It-Yourself) manufacturing; for example, properly located within a shopping mall they are able to directly interact with the customers, while being close to them in terms of design expectations, quality, environment, costs, and delivery time [12].

2.2. Industry 4.0 and Cyberphysical Systems (CPS): An Emerging Topic in Research. On the basis of an advanced digitalization within factories, the combination of Internet technologies and future-oriented technologies in the field of "smart" objects (machines/products) seems to result in a new paradigm shift in industrial production called also "Industry 4.0" [21]. After mechanization, electrification, and computerization of industrial production we are now with the Internet of Things (IoT) in the era of the so-called 4th industrial revolution or Industry 4.0. With the emerging trend of Industry 4.0 companies will connect and link their products, machines, storage/handling/transport systems, and other resources worldwide as cyberphysical systems (CPS) in the so-called "smart factories" [22]. Traditional products and manufacturing systems are becoming more and more multidisciplinary, intelligent, networked, and agile. However, not only consumer goods (i.e., smartphones) but also industrial goods are becoming "smart." Thus, the engineering of these smart products and systems will be of crucial importance for the competitiveness of industrial companies. There is a need for new smart engineering approaches, which also use the latest ICT innovation [23]. Several initiatives throughout industry and academia are emerging to address the next generation of advances in the IoT space, industrial Internet, and Internet of systems (IoS) and the exciting possibilities from research in cyberphysical systems [1,24].

The concept of Industry 4.0 is strongly related to the term cyberphysical systems (CPS) [24]. The term "cyberphysical systems" emerged around 2006, coined by Helen Gill at the National Science Foundation in the United States [25]. A cyberphysical system (CPS) is a combination of computers and physical systems (see also Figure 1). CPS is about the intersection, not the union, of the physical and the cyber world. It combines engineering models and methods with the models and methods of computer science [25]. Connecting physical world objects (made of atoms) with information (packaged as bits) may segue into another revolution, predicted by many, among whom is Neil Gershenfeld [1]. CPS positively affected manufacturing in form of cyberphysical production systems (CPPS) in process automation and control [26]. Due to the huge application potentials of CPS in manufacturing and yet the lack of common understanding of CPS in manufacturing sector, there is a need for further research of CPS [27]. Manufacturing will increasingly appear as equipped by physical and/or digital objectives, upgraded with sensing, processing, actuating, and networking capabilities. In addition, cyberphysical system may make network structures emerge as a result from collaborative processes executed by manufacturing units and customers as well as suppliers [28]. CPS capture data of the real world via sensors, process them with software from embedded controllers, use the Internet and cloud computing for mutual communication between the connectors, and interact with real world by means of mechatronic actuators [29]. The desired benefits are evident: intelligent, networked objects and autonomous control systems are able to reflect customer demands in real time [30].

Despite the benefits, concern about security is one of the biggest ones in the context of cloud manufacturing, cyberphysical systems, and distributed manufacturing. Often mentioned risks are concerns regarding valuable data and intellectual property rights $[31,32]$. These concerns should be regarded in the development of new business models for cyberphysical systems, cloud manufacturing, and distributed manufacturing. One aspect might be to establish trust by applying these concepts [33]. Proven case studies and robust processes and systems support building trust and reducing existing aversions [33]. A proactive risk management will be an important part to manage cyberphysical systems, cloud manufacturing, and distributed manufacturing systems [34]. This covers technical risks and attacks as well as all other risks which occur at interfaces (human, enterprises, supply chains, etc.). For risk mitigation, it is necessary to understand the possible threats of data-processing systems and assess them by considering the whole system as opposed to focusing only on risks for single components $[35,36]$. Hence, risk management should be discussed across the value chain and should be shared so that barriers to adoption will be reduced. 


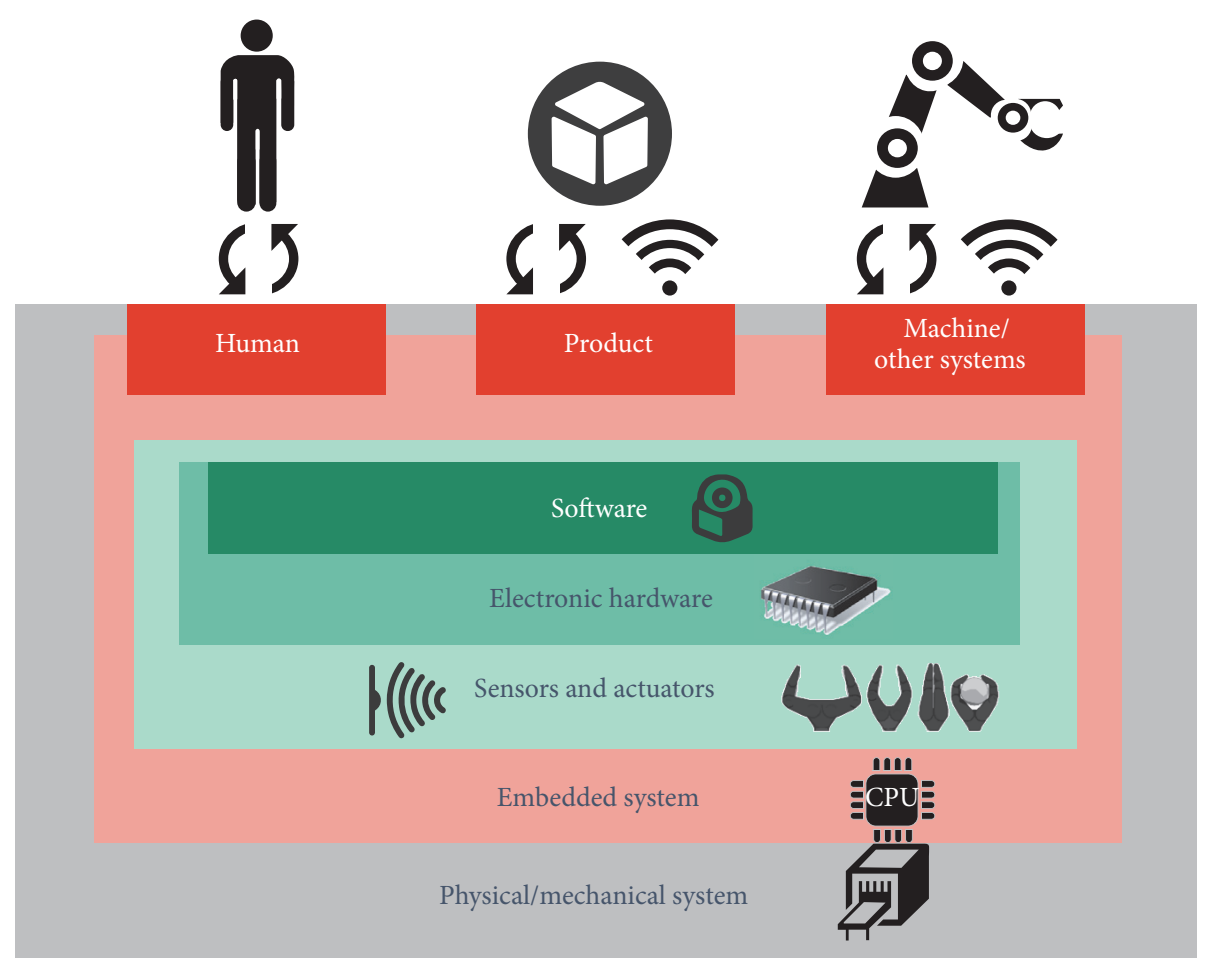

FIGURE 1: Layers of cyberphysical systems and interactions with their environment (adapted from [37]).

The growing demand for customized products in combination with decreasing product lifecycles asks for further transformation towards organization structures, which cope with increased complexity. Distributed systems can handle high complexity and form a starting point for the so-called cybernetic management, which incorporates self-controlling systems. The Internet has been identified as a powerful instrument to manage distributed systems [38]. In the past decades, advancements in web-based/Internet-based systems and applications have opened up the possibility for industries to utilize the cyberworkspace to conduct efficient and effective daily collaborations from anywhere in distributed manufacturing environments [27]. Advances on the fields of embedded systems and cyberphysical systems additionally accelerate the extension of distributed manufacturing from automated factory floors onto manufacturing enterprises level [25]. In the meantime, all critical technologies for smart distributed manufacturing systems are mature: sensor and actuator networks, intelligent controls, optimization software, cyberphysical systems, solutions for cybersecurity, and other related services are highly discussed in research and just available on the market. Powerful and efficient applications, available as cyberphysical systems, Internet of Things, pervasive computing, or machine-to-machine communication, will make distributed manufacturing a preferred model to produce [28].

\section{Collaborative Cloud Manufacturing (CCM)}

In this section, a framework for the application of cyberphysical systems in distributed manufacturing systems is presented by the concept of collaborative cloud manufacturing (CCM). Section 3.1 considers the overlap of cloud manufacturing and cyberphysical systems. Section 3.2 gives a short overview of different applicable business models for DMS and DMSnetworks. In Section 3.3, the concept of collaborative cloud manufacturing will be explained more in detail while Section 3.4 discusses business model architectures for CCM including cyberphysical systems. The section finally closes with a discussion of future challenges and possible application fields in industry.

3.1. Cloud Manufacturing and Cyberphysical Systems. Both cloud manufacturing and cyberphysical systems are fundamental elements in the overall topic of smart manufacturing. Kang et al. [39] classified both as a "core-technology" compared to other topics in the context of smart manufacturing, such as smart energy, intelligent automation, and the complex Internet of services. Due to the importance of both topicscloud manufacturing and cyberphysical systems-and their close connection, this section introduces what should be considered as a common platform, addressing what the differences are as well as what challenges remain.

The development of architectures and conceptual frameworks is the main activity in research and practice. For example, Karnouskos et al. [40] describe an IMC-AESOP architecture for cloud-based industrial cyberphysical systems and their framework of a service-oriented architecture covers such aspects as data handling, integration, monitoring, human-machine-interaction, lifecycle-management, and so forth. Yu et al. [41] classify both concepts as fitting the fourth industrial revolution, but, considered from an IT perspective, 
the concept of a cyberphysical system is product-centered compared to the concept of cloud manufacturing, which is more service-centered. Further, they describe that a "cyberphysical-system contributes to services networking though parts of it can also provide software-based services and cloud manufacturing is a service container and at the same time a service provider, inclusive of software and manufacturing services" [42].

In addition to the differences, there are still some challenges in the way to combine cloud manufacturing and cyberphysical systems, some of which are indicated by Karnouskos et al. [42], for example, the management of hundreds of devices, cross-layer collaboration, migration, and the impact of CPS on existing approaches as well as data science on CPS-empowered big data. In addition to these challenges, the adoption in the market will also depend on valuable, revenue-promising business model concepts or, in other words, promising and disruptive business model concepts might involve having to solve some issues and challenges and support the diffusion of cloud manufacturing and cyberphysical systems.

\subsection{Collaborative Cloud Manufacturing as Business Model} Concept for Distributed Manufacturing Systems and Networks. Modern forms of distributed manufacturing systems need also suitable business models to succeed in the market. New business models are required to meet the changes in the business logic [43]. To conceive how distributed manufacturing systems can be successfully applied in practice, a set of possible business models, which can be also described as business model clusters due to joint structure, has been proposed by the authors of [44] and is shown in Table 1.

(1) Microproduction Networks (MPN). This owner-based template is structured as a network of small sized minifactories for the production of goods for the local or regional market responding to the specific needs of customers. It shows opportunities for local entrepreneurs to open end develop/enlarge their own business without large investments.

(2) Contract Manufacturing Networks (CMN). This service-based template is applicable for service providers or cooperatives with a network of highly flexible and geographically distributed minifactories for contract manufacturing. Intermediaries ("production provider") bring globally acting clients and potential locally distributed manufacturer together.

(3) Mobile Factory Networks (MFN). This rental-based template is suitable for mobile non-location-bound and highly flexible as well as reconfigurable model factories for temporary production on-site. Commercialization is possible through rent of individually configured mobile factories and a centralized pool of standard modules.

(4) Production Franchise Networks (PFN). This franchisebased template shows a concept of DMS-factories operated independently by franchisees with more or less flexible and adaptable production units for geographically distributed production in a franchise network.

(5) Collaborative Cloud Manufacturing (CCM). This collaborative-based template enables active participation of the customer in the product development/configuration process through the use of innovative cloud solutions. Production begins with the transfer of product data from the platform to a network of distributed manufacturing systems.

According to the business model templates in Table $1 \mathrm{a}$ distributed manufacturing system can be designed by using one of the shown template models or a mix of different templates (e.g., a franchise production network combined with collaborative cloud manufacturing).

3.3. The Concept of Collaborative Cloud Manufacturing. The fundamental basis of collaborative cloud manufacturing is the organization of production units in collaborative networks. The organization in networks through collaborative manufacturing multiplies the available capacities without the need for further investments. Hence, companies in collaborative networks can adapt to volatile markets and shortened product lifecycles with high agility. In contrast to the many benefits, the decoupling and spatial separation of production units as well as handling of complex production data by multiple production-sites drastically increase the need for coordination [45]. Here are mainly new technologies and possibilities in cyberspace to support and facilitate coordination in collaborative networks by digital technologies reducing also complexity.

Next essential components of CCM are cloud computing and the concept of cloud manufacturing. The idea of "cloud manufacturing" is currently raising high expectations for the still-visionary value concept. In the future, industrial production changes in the medium and long term through the wider use of advanced manufacturing technologies by no longer selling the physical product but only the product data. The transport of products could be replaced in the future via the data transfer of product data according to visionary approaches. The products could then be manufactured and assembled in distributed networks of small factories with highly adaptive and changeable manufacturing systems and qualified staff for final assembling and finishing. Essential elements for realizing cloud manufacturing are digitalized manufacturing technologies, cyberphysical production systems, cloud computing, Internet of Things, semantic web, and high performance computing.

In collaborative cloud manufacturing, customers or users can access directly or through an external operated community to the manufacturing cloud. The manufacturing cloud is run by a manufacturing cloud operator who coordinates and develops the platform for product definition and configuration as well as the platform for order assignment to manufacturing resources provider in the collaborative network of DMS. CCM enables active participation and collaboration of the customer in the process for product definition or product configuration through the use of cloudbased and collective open-innovation tools according to the 
TABLE 1: Set of business models for distributed manufacturing systems.

Number Set of business models

Contract Manufacturing Networks (CMN)
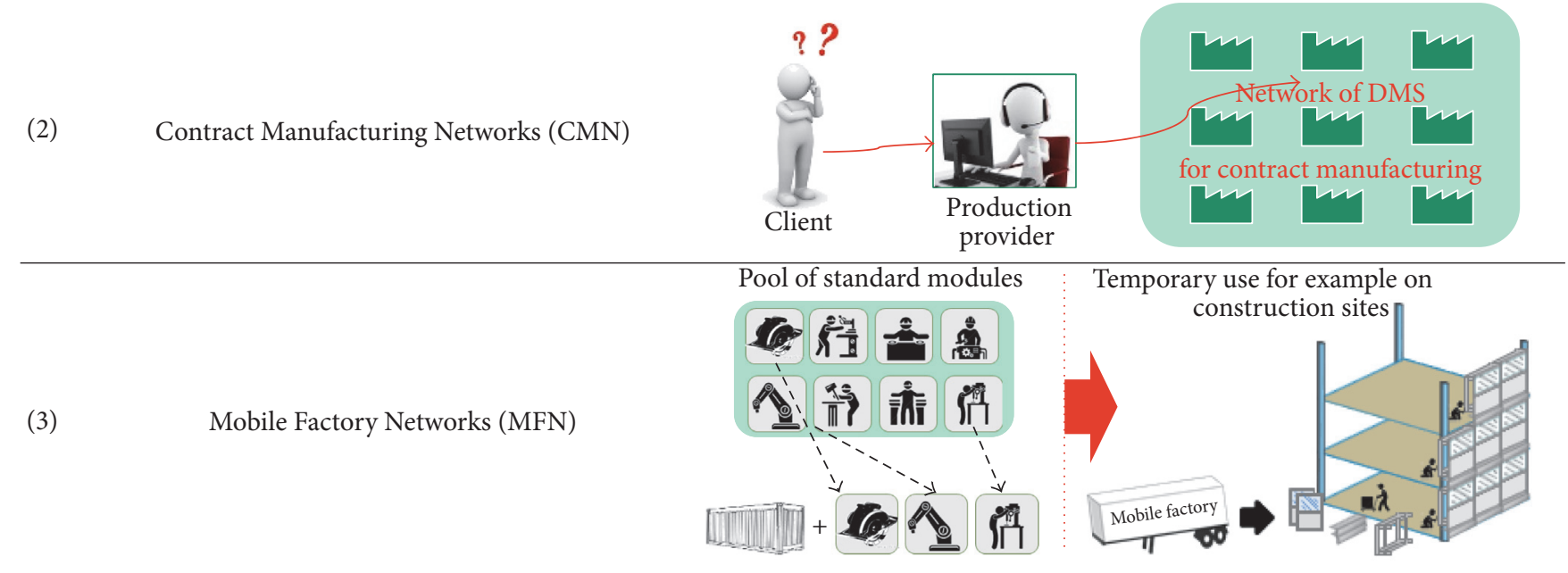

(4) Production Franchise Networks (PFN) Franchisor

$$
\text { Collaborative cloud manufacturing (CCM) }
$$
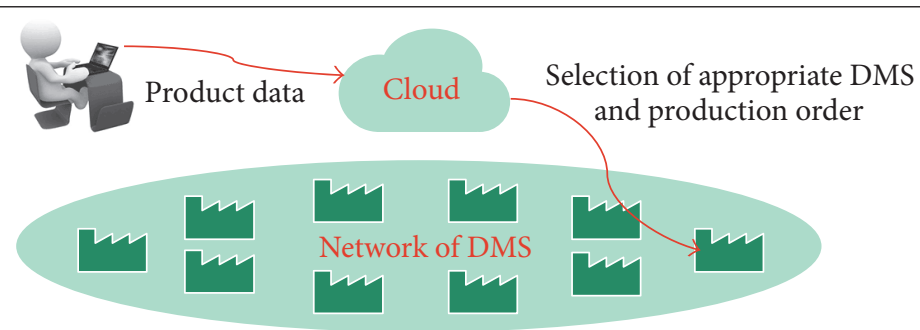

actual trend of democratization in design. In the broadest sense digital design and product development instruments are provided to the customers, with which they can create the product individually. When customer requirements have been recorded and product development is fulfilled, production begins with the transfer of product data from the platform to a pool of distributed manufacturing systems that identify the nearest production unit in the network with free production capacity to meet the agreed delivery date. The ordered product is then produced in the identified production unit and finally delivered to the customer or provided for pickup by the customer itself. Pervasive and efficient allocation and coordination of resources and free capacities or capabilities can be achieved by a centralized and intelligent manufacturing cloud solution (see Figure 2).

3.4. Design of Business Model Innovations Based on Collaborative Cloud Manufacturing. Business models as "business logic" display the logic of value generation and value capturing. Therefore, the two business model elements as described in Section 1, "value proposition" and "revenue," typically define the added value provided by the business model as well 


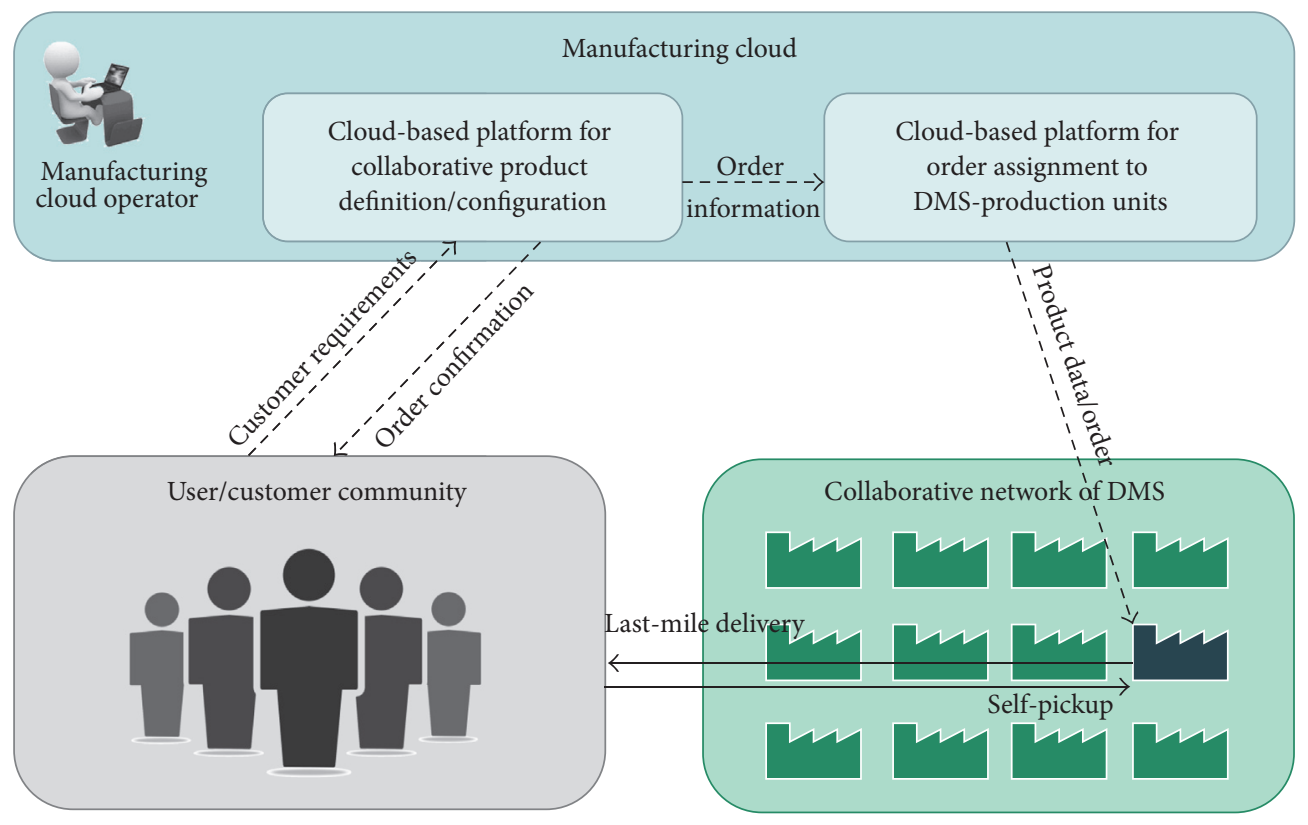

FIGURE 2: Concept of collaborative cloud manufacturing (CCM).

as what profits can be achieved based on the costs involved. In particular, in a distributed manufacturing network environment, the cost structure of the assigned manufacturing units and their price-finding logic are important components in the business model. Depending on the business model concept, value can be generated and captured on the value proposition side as well as on the pricing logic and cost side. Additionally, the generated value will be mostly shared, so that all or some of the involved units and users can capture part of the generated value.

In addition to the benefits of an intelligent manufacturing cloud solution and the advantages generated by using distributed manufacturing networks and units, the adoption of the collaborative cloud manufacturing concept and its individual emerged business models could be dependent on the relationship between customer added value, price, cost, and willingness to pay. Based on this relationship, Matzler et al. [46] illustrate three types of business model innovations, which are shown in Figure 3 and will be discussed further.

Option A features an extended customer added value, enabled by reduced costs, which might be caused by a different principle of cost structure and increased efficiency in production. An enhanced profit can be also achieved so that both sides can participate and capture value. Enablers of this type of business model innovation are emerged and combined technologies in terms of cyberphysical systems.

Business model innovations based on Option B are often provided by technological innovations and an additional added value in comparison to other available technology and manufacturing approaches. As such, the customer is willing to pay more and the offering unit can request a higher price. Despite the mostly increased R\&D effort for developing and implementing the technology innovation, the production unit is able to achieve a higher profit and can cut cost, especially in the long run.

Option C covers cases of differentiation in value chain and value generation, so that the business models allow reduced prices, although the overall customer benefit and willingness to pay are decreased. However, the perceived customer added value is increased in relation to benefit reduction. As a result of the differentiated business architecture the cost structure can be reduced and, consequently, increase profit.

These three options schematically illustrate three business model types and their business logic architecture. In designing new business models for CCM, there is a need to discuss which options exist to extend customer added value and profit.

Osterwalder et al. [47] recommends defining a clear value proposition to clarify customer profiles and identify customer gains and pains. As well as a clear value proposition, what customer integration looks like and how shared value generation can be achieved need to be addressed. Value is not limited to economic value; social and environmental value and other factors can be valuable to the customer too. For instance, gaining knowledge and power sharing are motivators in coproduction and co-value-creation [48]. Furthermore, it is also necessary to consider if the value proposition is tangible, intangible, or a combination of both. In this context, the aim is to extend customer added value. In most cases, the customer validates the offered value proposition in comparison to alternative offers and options which are available. Anderson et al. [49] propose that, for business markets, the value proposition should include favorable points of difference. The theory of diffusion suggests the same thing and emphasises that the adoption of innovation is dependent on the relative advantage which 

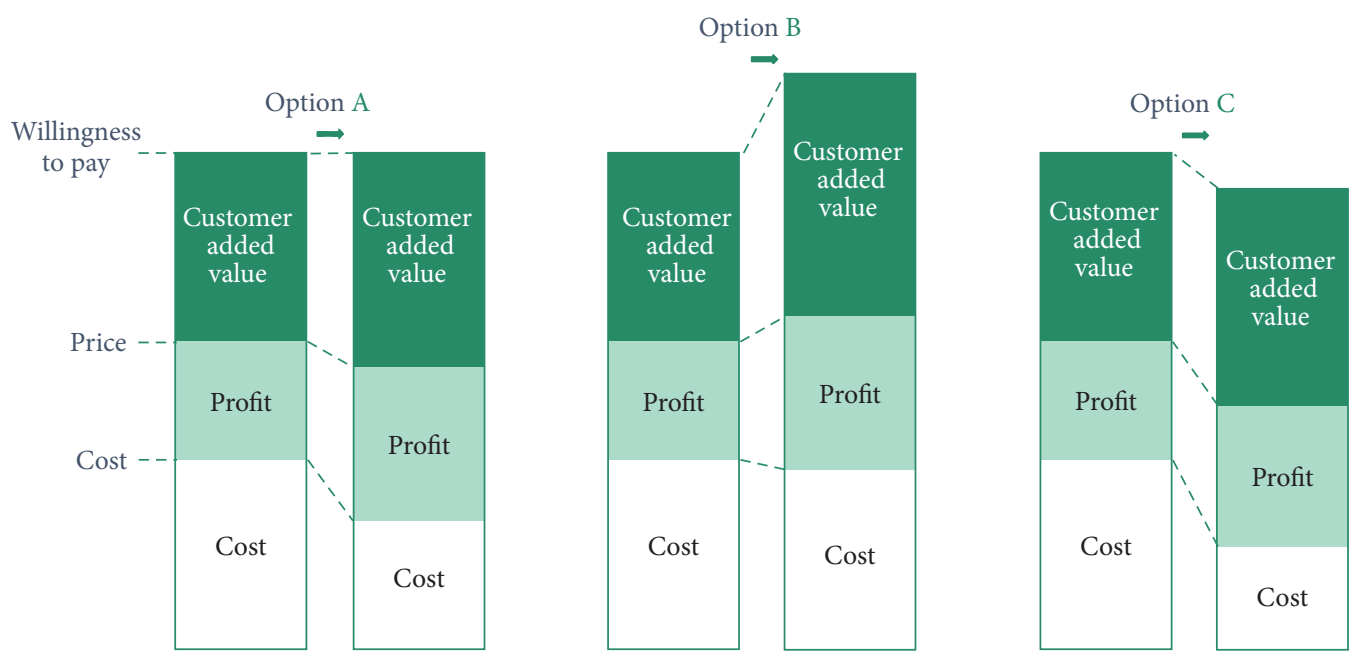

FIgURE 3: Common design options to achieve business model innovations [46].

describes the degree of favorability over the existing offer in terms of the market concepts, products, and so forth [50]. In this case, the higher the perceived benefits compared to the same offers, the greater the likelihood of adoption of the innovation [51]. The theory of diffusion is based on research findings by Rogers [52] and these have been confirmed in many analyses over the past decades. Rogers pointed out that the diffusion of innovations depends mainly on five factors, namely, relative advantage, compatibility, trialability, complexity, and observability. Some meta-analysis has added the factor of perceived risks as a sixth factor. These six factors explain the diffusion rate of innovation up to $87 \%[50,53]$. Cloud manufacturing systems, cyberphysical systems, and distributed manufacturing systems are new concepts which can be classified as technical or organizational innovations. This argumentation can be also followed by consideration that cloud manufacturing systems, cyberphysical systems, and distributed manufacturing systems are facing barriers which prevent adoption by the market. Such barriers are security concerns, perceived complexity, missing use cases, and applicability in practice $[18,54]$. Managerial consequences to increase the diffusion rate of cloud manufacturing systems, cyberphysical systems, and distributed manufacturing systems should be to consider the six factors of the theory of diffusion in the designing phase of these concepts. In particular, for CPS, Mikusz [55] underlines the importance of standardization and interoperationability which can also be derived from the theory of diffusion. Compatibility of systems influences diffusion in the market, so that the value proposition is aligned with the existing technical as well as social systems. Trialability of the value proposition should be given as well. Scalable production is required to reduce possible adopter barriers and provide flexibility for the customer. The objective is to extend the customer added value by designing the value proposition.

Customer added value can also be a changed revenue model which has better suitability for customer needs and doing business. Depending on the value proposition, on what base the revenues and prices should be calculated needs to be taken into account. The calculation base can be output (unit), duration of provision, performance level, or usage [56]. The first type of calculation base represents the common model to achieve revenues by selling the produced units. The calculation base "duration of provision" has a revenue and pricing model dependent on the period for which the services are provided. The performance level as calculation base uses predefined performance parameters to calculate the revenues. The achievement of revenues based on the usage of the value creation depends directly on customer consumption. By applying this type, customer behaviour (usage) is the input parameter, in contrast to the third type, and the level of performance is the output parameter, on which the achievement of revenue depends.

IT and data-driven business models emerging in recent years have shown that, besides common value exchange, other possibilities of achieving revenues also exist. These forms are often referred to as indirect forms due to the fact that the value exchange and relationship are complemented by a third party. Cyberphysical systems and usage of data as commercial asset might be able to establish such kind of revenue achievement as well as a combination of direct and indirect revenue achievement [6].

In addressing the question of how to achieve revenues, one should consider which pricing approach is the most appropriate in supporting capturing the generated value and which logic for pricing formation can be used.

The price will mostly be defined by the relation between vendor, buyer, and competitor. In general, we can distinguish different pricing approaches which can be followed and combined as the pricing concept within the designed business model. Here, we differentiate between a demand-driven, competition-driven, and cost-driven pricing approach [57]. Demand-driven pricing depends directly on the demand and the willingness of the customer to pay, whereas competitiondriven pricing is explicitly related to market conditions and is based on price-setting by the competition and its 
pricing behaviour. It is particularly appropriate when the reaction of consumers to the conduct of competitors can be measured. Cost-driven approach is based on production cost with an additional mark-up. This is particularly true in competitive markets and, for strategic reasons, when first entering established markets, where the costs are the distinctive determinant and services are easily replaceable, and, therefore, a cost-based pricing policy may be appropriate. It should be emphasised that the competition-driven and costdriven pricing approaches also take into account willingness to pay; however, in the demand-driven approach, willingness to pay is the core of the price formation.

The mechanism of price finding and the possibilities of negotiations are also parameters that should be considered. In general, we distinguish between nonfixed, unilateral fixed, and two-sided fixed pricing [57]. A unilateral fixing of price formation provides that, whether provided by the suppliers or on the part of the buyer, the price is set and binding and the other side has no influence on pricing. With two-sided fixing, both the supply and the demand side offer quotations and the pricing is done by predetermined rules. Free pricing in the form of negotiations is referred to in this context as nonfixed pricing.

By adapting of parameters of value proposition and/or revenue model one of the three options displayed in Figure 3 should be targeted, so that a changed business model architecture enables providing an extended customer added value, to reach a higher profit range and/or reduce costs. Cyberphysical systems will be the leverage to change business logic and applying and spreading distributed manufacturing systems.

\section{Discussion}

It has emerged that, in the past, high potential and technically mature technologies and new organizational approaches (including those in manufacturing) have struggled with their diffusion in the market. Sustainable production with minimized logistic costs and individualized products for regional markets can be provided by distributed manufacturing systems. Collaborative cloud manufacturing and cyberphysical systems enable and support the trend towards decentralized manufacturing systems. Active participation and collaboration of the customer in the process for product definition or product configuration are one benefit of collaborative cloud manufacturing providing actual trend of democratization in design. Cyberphysical systems as provider to change the principles in production planning shift the production planning intelligence to the individual current generating product. This might be the leverage for a paradigm change from centralized production concepts to decentralized and distributed manufacturing systems. Beside the advantages of all three concepts the challenging part is to reduce the barriers for diffusion in practice. Therefore, research activities should consider how the diffusion of collaborative cloud manufacturing (CCM), distributed manufacturing systems (DMS), and cyberphysical systems (CPS) can be supported.

Sustainable business models and success stories might be useful in terms of finding more and more people to adopt these concepts and approaches. A systemic development approach, as is known and practiced in many other disciplines, can support these developers in identifying and developing changed business architectures which fit these concepts and exploits.

Breaking down the business model and its elements and an analysis of possibilities of generating and capturing value from the beginning are appropriate to align all the components of the collaborative manufacturing unit. A description of general options in designing business model elements might be valuable for creating and gathering new ideas which are different to the existing processes in business. Creativity research suggests that knowledge can be a barrier to thinking "out of the box"; however, in most cases, without knowledge, the result of an idea-generation process cannot be used due to the lack of detail and leverage to challenge existing proven concepts. Nevertheless, being different is not the only objective in altered and new business logic; additionally, how to extend customer added value and/or profit as well as how a reduction of costs can be achieved and how components fit together should all be considered. The options proposed by Matzler et al. [46] are common possibilities for adapting business model architectures compared to existing ones, with the result of achieving a design for a sustainable business model and boosting the concepts of CCM, DMS, and CPS.

The prevalidation of the attractiveness of designed business models can be done by considering the five or six factors of the theory of diffusion. Manufacturing companies need to assess whether the concepts of CCM, DMS, and CPS provide benefits compared to the currently used or other existing systems and should seek to reduce risks to achieve easy and effective adoption. Therefore, these six factors should be considered in the design phase of new business models and should be used as first proof before the business model is launched.

\section{Conclusion and Further Research Work}

Megatrends, like sustainability and mass customization and democratization, offer a change of production paradigm and require more and more distributed manufacturing systems. CCM and CPS are two additional topics which fit the DMS and suppose a completely different production approach and father a new kind of value generation. Enabled by these possibilities, the commercial side of processes should also be considered and should support the diffusion of these concepts. Therefore, business model innovation is a management discipline which is becoming more and more popular in practice and research in recent years and is suitable for application in the case of DMS and CCM as well. After its introduction in DMS and a set of business models developed from technical processes, CCM is explained in more detail and connected to CPS. CCM and CPS have the potential to establish a new generation of value creation, value capture, and value sharing. Different business model architectures mostly involve the requirement of realizing a different way of doing business and offering value. There are general options to adapt business models which are discussed and components of business model design which are provided in 
order that ideas for new business models, in particular, have the potential to be business model innovations which can be created and developed.

This paper contributes to discussing common options for changing business model architectures and challenging establish market players and concepts through new business models. Depending on the willingness to pay, the extent of customer added value and the price and cost level of business model adoptions should be considered in designing new business models. These general options are discussed in the context of distributed manufacturing systems provided by the new possibilities of cloud manufacturing and cyberphysical systems and support the process to develop new business model architectures based on these systems and technologies. This paper also introduces the criteria to be considered in the assessment of development of business model architectures and provides an indication of adoption attractiveness in the market.

Further research work should apply these general options and extend the range of options. It might be interesting to see how systematic approaches can be used to design and develop systems, for instance, Axiomatic Design, to set up business models for CCM. Quantitative research might also be very valuable to identify the barriers which exist in the use of CCM, DMS, and CPS. These findings could be useful in reducing barriers, adapting research activities, and supporting the diffusion process for these concepts in order to share value provided by CCM.

\section{Competing Interests}

The authors declare that they have no competing interests.

\section{Acknowledgments}

This research is part of actual research activities in the project DIMASY that are titled "Design of Decentralized and Distributed Manufacturing Systems and Their Coordination in Manufacturing Networks" and is supported by the Free University of Bolzano (Italy) in collaboration with the research institute Fraunhofer Italia Research s.c.a.r.l., Innovation Engineering Center (IEC), and the SME company Tecnomag GmbH (Italy).

\section{References}

[1] S. P. A. Datta, "Dynamic socio-economic disequilibrium catalyzed by the Internet of Things," http://dspace.mit.edu/bitstream/handle/1721.1/86935/Dynamic\%20Socio-Economic\% 20Disequilibrium\%20_\%20Shoumen\%20Datta.pdf?sequence= 226.

[2] UNIDO, Emerging Trends in Global Manufacturing Industries, United Nations Industrial Development Organization, 2013, https://www.unido.org/fileadmin/user_media/Services/PSD/ Emerging_Trends_UNIDO_2013.PDF.

[3] R. P. Ortiz, B. Ramis-Ferrer, E. Miedes, A. Nieto, R. Juan-Marín, and J. Martínez-Lastra, "Towards a cloud-based platform for enabling supply chain collaboration," in Proceedings of the 8th International Conference in Interoperability for Enterprise Systems and Applications, Guimares, Portugal, April 2016.

[4] R. Casadesus-Masanell and F. Zhu, "Business model innovation and competitive imitation: the case of sponsor-based business models," Strategic Management Journal, vol. 34, no. 4, pp. 464482, 2013.

[5] P. Spieth and S. Schneider, "Business model innovativeness: designing a formative measure for business model innovation," Journal of Business Economics, vol. 86, no. 6, pp. 671-696, 2016.

[6] S. Datta, "Internet of Systems (IoS)-Economic Re-equilibration Catalyzed by Internet of Things (IoT)," 2014, https://dspace .mit.edu/handle/1721.1/86935.

[7] E. Rauch, M. Dallinger, P. Dallasega, and D. T. Matt, "Sustainability in manufacturing through distributed manufacturing systems (DMS)," Procedia CIRP, vol. 29, pp. 544-549, 2015.

[8] S. Schmid and P. Grosche, "Glocal value in the Volkswagen Group-towards more decentralization of production and development," ESCP-EAP Working Paper 41, European School of Management, Berlin, Germany, 2008.

[9] S. Bednar and V. Modrak, "Mass customization and its impact on assembly process' complexity," International Journal for Quality Research, vol. 8, no. 3, pp. 417-430, 2014.

[10] V. Modrak, S. Bednar, and D. Marton, "Generating product variations in terms of mass customization," in Proceedings of the 13th IEEE International Symposium on Applied Machine Intelligence and Informatics (SAMI '15), pp. 187-192, Herl'any, Slovakia, January 2015.

[11] D. Mourtzis and M. Doukas, "Decentralized manufacturing systems review: challenges and outlook," in Robust Manufacturing Control: Proceedings of the CIRP Sponsored Conference RoMaC 2012, Bremen, Germany, 18th-20th June 2012, Lecture Notes in Production Engineering, pp. 355-369, Springer, Berlin, Germany, 2013.

[12] C. Zanetti, M. Seregni, M. Bianchini, and M. Taisch, "A production system model for Mini-Factories and last mile production approach," in Proceedings of the IEEE 1st International Forum on Research and Technologies for Society and Industry Leveraging a better tomorrow (RTSI'15), pp. 451-456, Torino, Italy, September 2015.

[13] D. Mourtzis, M. Doukas, and F. Psarommatis, "Design and planning of decentralised production networks under high product variety demand," Procedia CIRP, vol. 3, pp. 293-298, 2012.

[14] D. Mourtzis and M. Doukas, "Design and planning of manufacturing networks for mass customisation and personalisation: challenges and outlook," Procedia CIRP, vol. 19, pp. 1-13, 2014.

[15] D. T. Matt and E. Rauch, "Design of a scalable modular production system for a two-stage food service franchise system," International Journal of Engineering Business Management, vol. 4, no. 2, pp. 1-10, 2012.

[16] M. Seregni, C. Zanetti, and M. Taisch, Development of Distributed Manufacturing Systems (DMS) Concept, Summer School "Francesco Turco"-Industrial Systems Engineering, Naples, Italy, 2015.

[17] E. Rauch, D. T. Matt, and P. Dallasega, "Mobile Factory Network (MFN)-network of flexible and agile manufacturing systems in the construction industry," Applied Mechanics and Materials, vol. 752-753, pp. 1368-1373, 2015.

[18] P. Helo, M. Suorsa, Y. Hao, and P. Anussornnitisarn, "Toward a cloud-based manufacturing execution system for distributed manufacturing," Computers in Industry, vol. 65, no. 4, pp. 646656, 2014. 
[19] D. Wu, M. J. Greer, D. W. Rosen, and D. Schaefer, "Cloud manufacturing: strategic vision and state-of-the-art," Journal of Manufacturing Systems, vol. 32, no. 4, pp. 564-579, 2013.

[20] L. Yao, Y. Wang, Y. Kong, X. Cheng, and L. Ren, "Integrating desktop factory into manufacturing cloud: a conceptual model," in Proceedings of the International Conference on Computer Information Systems and Industrial Applications, Atlantis Press, Bangkok, Thailand, June 2015.

[21] H. Lasi, P. Fettke, H.-G. Kemper, T. Feld, and M. Hoffmann, "Industry 4.0," Business \& Information Systems Engineering, vol. 6, no. 4, pp. 239-242, 2014.

[22] H. Kagermann, W. Wahlster, and J. Helbig, Deutschlands Zukunft als Produktionsstandort sichern, Umsetzungsempfehlungen für das Zukunftsprojekt Industrie, 4.0, 2013.

[23] M. Abramovici, J. C. Göbel, and M. Neges, "Smart engineering as enabler for the 4th industrial revolution," in Integrated Systems: Innovations and Applications, M. Fathi, Ed., pp. 163170, Springer, Berlin, Germany, 2015.

[24] IIC, "Overview of the Industrial Internet Consortium. Presentation," http://www.iiconsortium.org/ma-14/Industrial_Internet_ Consortium_Information_Day_June_17_2014.pdf.

[25] E. A. Lee, "The past, present and future of cyber-physical systems: a focus on models," Sensors, vol. 15, no. 3, pp. 48374869, 2015

[26] L. Monostori, "Cyber-physical production systems: roots, expectations and R\&D challenges," Procedia CIRP, vol. 17, pp. 9-13, 2014.

[27] L. Wang, M. Törngren, and M. Onori, "Current status and advancement of cyber-physical systems in manufacturing," Journal of Manufacturing Systems, vol. 37, pp. 517-527, 2015.

[28] H. Kuehnle, "Distributed Manufacturing (DM)-Smart Units and Collaborative Processes," World Academy of Science, Engineering and Technology, International Journal of Social, Behavioral, Educational, Economic, Business and Industrial Engineering, vol. 9, no. 4, pp. 1227-1238, 2015.

[29] E. A. Lee, "Cyber physical systems: design challenges," in Proceedings of the 11th IEEE Symposium on Object/Component/Service-Oriented Real-Time Distributed Computing (ISORC '08), pp. 363-369, May 2008.

[30] D. Spath, S. Gerlach, M. Hämmerle, S. Schlund, and T. Strölin, "Cyber-physical system for self-organised and flexible labour utilisation," in Proceedings of the 22nd International Conference on Production Research (ICPR '13), 2013.

[31] C. W. Axelrod, "Managing the risks of cyber-physical systems," in Proceedings of the Systems, Applications and Technology Conference (LISAT '13), pp. 1-6, IEEE, Farmingdale, NY, USA, 2013.

[32] S. Amin, G. A. Schwartz, and A. Hussain, "In quest of benchmarking security risks to cyber-physical systems," IEEE Network, vol. 27, no. 1, pp. 19-24, 2013.

[33] A. Pereira, N. Rodrigues, J. Barbosa, and P. Leitão, “Trust and risk management towards resilient large-scale cyber-physical systems," in Proceedings of the IEEE International Symposium on Industrial Electronics (ISIE '13), pp. 1-6, IEEE, Taipei, Taiwan, May 2013.

[34] E. Chang and T. Dillon, "Trust, reputation, and risk in cyber physical systems," in Artificial Intelligence Applications and Innovations, H. Papadopoulos, A. S. Andreou, L. Iliadis, and L. Maglogiannis, Eds., IFIP Advances in Information and Communication Technology, pp. 1-9, 2013.
[35] M. J. Hutchins, R. Bhinge, M. K. Micali, S. L. Robinson, J. W. Sutherland, and D. Dornfeld, "Framework for identifying cybersecurity risks in manufacturing," Procedia Manufacturing, vol. 1, pp. 47-63, 2015.

[36] Y. Peng, T. Lu, J. Liu, Y. Gao, X. Guo, and F. Xie, “Cyber-physical system risk assessment," in Proceedings of the 9th International Conference on Intelligent Information Hiding and Multimedia Signal Processing (IIH-MSP '13), pp. 442-447, IEEE, Beijing, China, October 2013.

[37] M. Broy, Cyber-Physical Systems: Innovation Durch Softwareintensive Eingebettete Systeme, Springer, Berlin, Germany, 2010.

[38] M. Brettel, N. Friederichsen, M. Keller, and M. Rosenberg, "How virtualization, decentralization and network building change the manufacturing landscape: an industry 4.0 perspective," International Journal of Mechanical, Industrial Science and Engineering, vol. 8, no. 1, pp. 37-44, 2014.

[39] H. S. Kang, J. Y. Lee, S. Choi et al., "Smart manufacturing: past research, present findings, and future directions," International Journal of Precision Engineering and Manufacturing-Green Technology, vol. 3, no. 1, pp. 111-128, 2016.

[40] S. Karnouskos, A. W. Colombo, T. Bangemann et al., "The IMCAESOP architecture for cloud-based industrial cyber-physical systems," in Industrial Cloud-Based Cyber-Physical Systems: The IMC-AESOP Approach, M. Tilly, M. Sikora, F. Jammes et al., Eds., pp. 49-88, Springer, Berlin, Germany, 2014.

[41] C. Yu, X. Xu, and Y. Lu, "Computer-integrated manufacturing, cyber-physical systems and cloud manufacturing-concepts and relationships," Manufacturing Letters, vol. 6, pp. 5-9, 2015.

[42] S. Karnouskos, A. W. Colombo, and T. Bangemann, "Trends and challenges for cloud-based industrial cyber-physical systems," in Industrial Cloud-Based Cyber-Physical Systems: The IMC-AESOP Approach, A. W. Colombo, T. Bangemann, S. Karnouskos et al., Eds., pp. 231-240, Springer, Berlin, Germany, 2014.

[43] C. M. Christensen, J. H. Grossman, and J. Hwang, The Innovator's Prescription: A Disruptive Solution for Health Care, McGraw-Hill, New York, NY, USA, 2009.

[44] D. T. Matt, E. Rauch, and P. Dallasega, "Trends towards distributed manufacturing systems and modern forms for their design," in Proceedings of the International Conference on Intelligent Computation in Manufacturing Engineering (ICME '15), vol. 33, pp. 185-190, Capri, Italy, 2015.

[45] D. M. Jaehne, M. Li, R. Riedel, and E. Mueller, "Configuring and operating global production networks," International Journal of Production Research, vol. 47, no. 8, pp. 2013-2030, 2009.

[46] K. Matzler, F. Bailom, S. F. von den Eichen, and T. Kohler, "Business model innovation: coffee triumphs for Nespresso," Journal of Business Strategy, vol. 34, no. 2, pp. 30-37, 2013.

[47] A. Osterwalder, Y. Pigneur, G. Bernarda, and A. Smith, Value Proposition Design, John Wiley \& Sons, New Jersey, NJ, USA, 2014.

[48] K. R. Ranjan and S. Read, "Value co-creation: concept and measurement," Journal of the Academy of Marketing Science, vol. 44, no. 3, pp. 290-315, 2016.

[49] J. C. Anderson, J. A. Narus, and W. van Rossum, "Customer value propositions in business markets," Harvard Business Review, vol. 84, no. 3, pp. 90-99, 2006.

[50] E. M. Rogers, Diffusion of Innovations, Free Press, New York, NY, USA, 5th edition, 2003.

[51] H. Makkonen, W. J. Johnston, and R. G. Javalgi, "A behavioral approach to organizational innovation adoption," Journal of Business Research, vol. 69, no. 7, pp. 2480-2489, 2016. 
[52] E. M. Rogers, Diffusion of Innovations, Free Press, New York, NY, USA, 1962.

[53] I. Sahin, "Detailed review of rogers' diffusion of innovations theory and educational technology-related studies based on Rogers' theory," The Turkish Online Journal of Educational Technology, vol. 5, no. 2, pp. 14-23, 2006.

[54] T. Lu, B. Xu, X. Guo, L. Zhao, and F. Xie, "New multilevel framework for cyber-physical system security," 2013, https:// www.terraswarm.org/pubs/136/lu_newmultiframe_edge.pdf.

[55] M. Mikusz, "Towards an understanding of cyber-physical systems as industrial software-product-service systems," Procedia CIRP, vol. 16, pp. 385-389, 2014.

[56] S. Seidenstricker and C. Linder, "A morphological analysisbased creativity approach to identify and develop ideas for BMI: a case study of a high-tech manufacturing company," International Journal of Entrepreneurship and Innovation Management, vol. 18, no. 5-6, pp. 409-424, 2014.

[57] R. Klein and C. Steinhardt, Revenue Management, Springer, Berlin, Germany, 2008. 


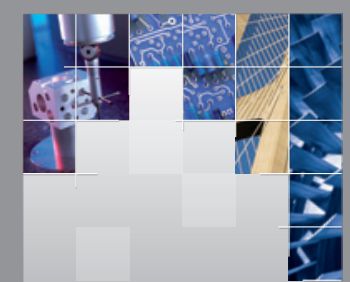

\section{Enfincering}
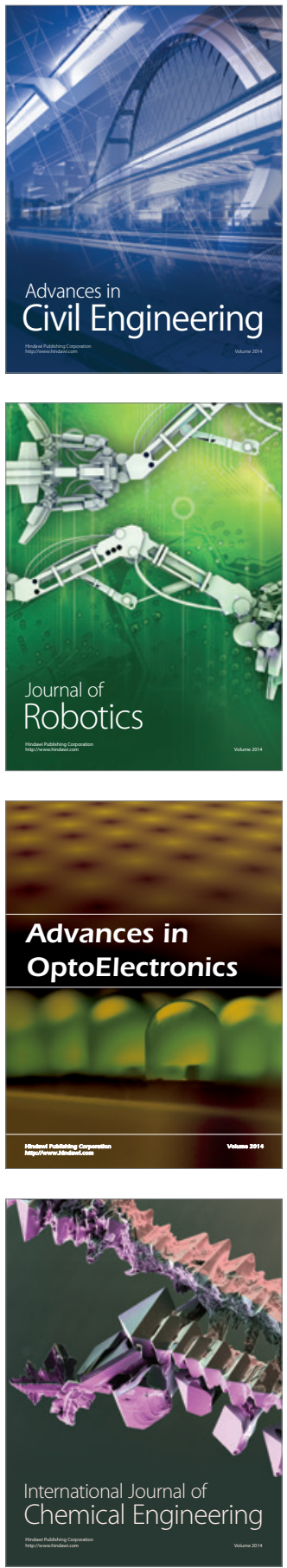

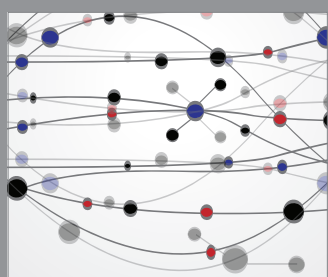

The Scientific World Journal

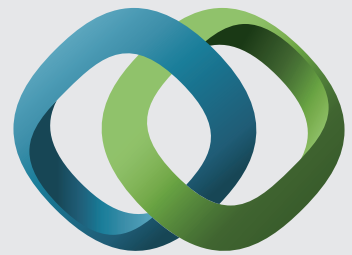

\section{Hindawi}

Submit your manuscripts at

http://www.hindawi.com
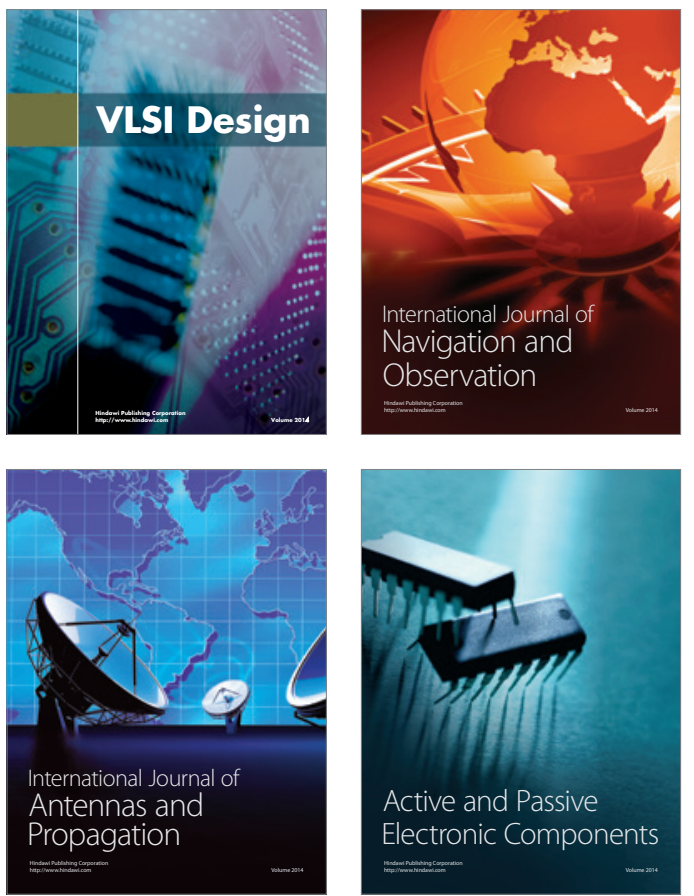
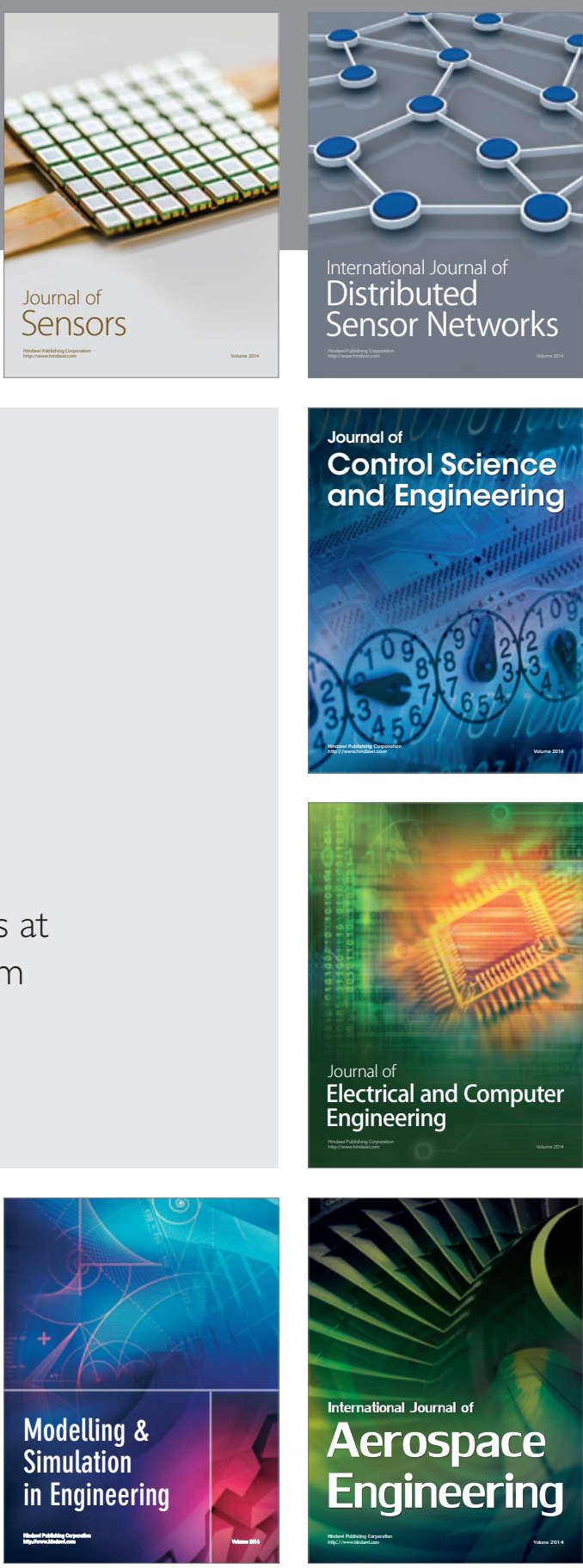

International Journal of

Distributed

Sensor Networks

Journal of

Control Science

and Engineering
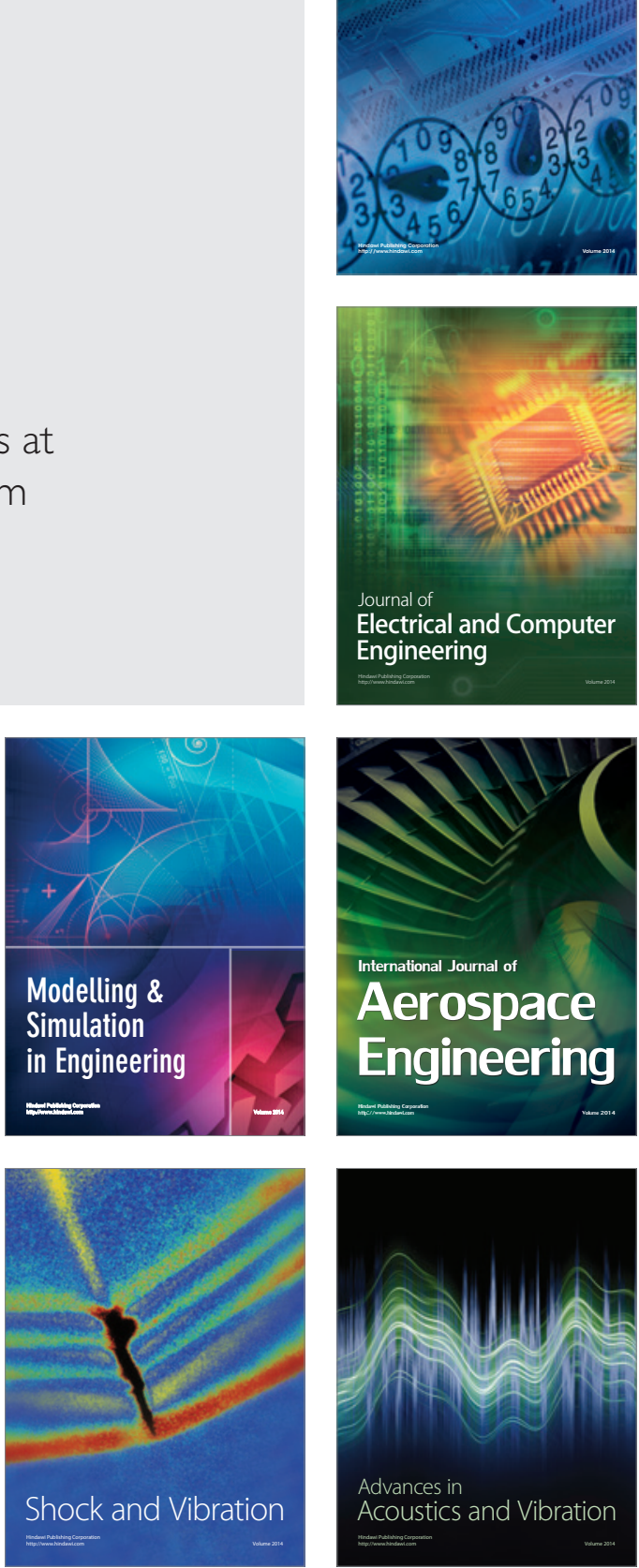